\title{
The endogenous cannabinoid system affects energy balance via central orexigenic drive and peripheral lipogenesis
}

\author{
Daniela Cota, ${ }^{1}$ Giovanni Marsicano, ${ }^{2}$ Matthias Tschöp, ${ }^{3}$ Yvonne Grübler, ${ }^{1}$ \\ Cornelia Flachskamm, ${ }_{4}^{4}$ Mirjam Schubert,${ }^{5}$ Dorothee Auer, ${ }^{5}$ Alexander Yassouridis, ${ }^{6}$ \\ Christa Thöne-Reineke, ${ }^{7}$ Sylvia Ortmann, ${ }^{8}$ Federica Tomassoni, ${ }^{9}$ Cristina Cervino, ${ }^{9}$ \\ Enzo Nisoli, ${ }^{10}$ Astrid C.E. Linthorst, ${ }^{4}$ Renato Pasquali, ${ }^{9}$ Beat Lutz, ${ }^{2}$ Günter K. Stalla, ${ }^{1}$ \\ and Uberto Pagotto ${ }^{9}$
}

${ }^{1}$ Clinical Neuroendocrinology Group and

${ }^{2}$ Molecular Genetics of Behavior Group, Max-Planck-Institute of Psychiatry, Munich, Germany

${ }^{3}$ Department of Pharmacology, German Institute of Human Nutrition, Bergholz-Rehbrücke, Germany

${ }^{4}$ Neurochemistry Group,

${ }^{5}$ Magnetic Resonance Imaging and Spectroscopy Group, and

${ }^{6}$ Biostatistics Group, Max-Planck-Institute of Psychiatry, Munich, Germany

${ }^{7}$ Max-Rubner-Laboratory, German Institute of Human Nutrition, Bergholz-Rehbrücke, Germany

${ }^{8}$ Institute for Zoo and Wildlife Research, Berlin, Germany

${ }^{9}$ Endocrinology Unit and Centro di Ricerca Biomedica Applicata, Sant Orsola-Malpighi Hospital, Bologna, Italy

${ }^{10}$ Center for Study and Research on Obesity, Department of Preclinical Sciences, School of Medicine, University of Milan,

Laboratori Interdisciplinari di Tecnologie Avanzate Vialba, Luigi Sacco Hospital, Milan, Italy

The cannabinoid receptor type 1 (CB1) and its endogenous ligands, the endocannabinoids, are involved in the regulation of food intake. Here we show that the lack of $C B 1$ in mice with a disrupted $C B 1$ gene causes hypophagia and leanness. As compared with WT $\left(\mathrm{CB1}^{+/+}\right)$littermates, mice lacking $\mathrm{CB} 1\left(\mathrm{CB1}^{-/-}\right)$ exhibited reduced spontaneous caloric intake and, as a consequence of reduced total fat mass, decreased body weight. In young $\mathrm{CB1} 1^{-/-}$mice, the lean phenotype is predominantly caused by decreased caloric intake, whereas in adult $\mathrm{CB1}^{-/-}$mice, metabolic factors appear to contribute to the lean phenotype. No significant differences between genotypes were detected regarding locomotor activity, body temperature, or energy expenditure. Hypothalamic CB1 mRNA was found to be coexpressed with neuropeptides known to modulate food intake, such as corticotropin-releasing hormone (CRH), cocaine-amphetamine-regulated transcript (CART), melanin-concentrating hormone $(\mathrm{MCH})$, and prepro-orexin, indicating a possible role for endocannabinoid receptors within central networks governing appetite. $\mathrm{CB1}^{-/-}$mice showed significantly increased CRH mRNA levels in the paraventricular nucleus and reduced CART mRNA levels in the dorsomedial and lateral hypothalamic areas. CB1 was also detected in epidydimal mouse adipocytes, and CB1-specific activation enhanced lipogenesis in primary adipocyte cultures. Our results indicate that the cannabinoid system is an essential endogenous regulator of energy homeostasis via central orexigenic as well as peripheral lipogenic mechanisms and might therefore represent a promising target to treat diseases characterized by impaired energy balance.

J. Clin. Invest. 112:423-431 (2003). doi:10.1172/JCI200317725.

Received for publication December 30, 2002, and accepted in revised form April 15, 2003.

Address correspondence to: Uberto Pagotto, Department of Internal Medicine and Gastroenterology, Endocrinology Unit and C.R.B.A., S. Orsola-Malpighi Hospital, 40138 Bologna, Italy. Phone: 39-051-6363009; Fax: 39-051-6363080;

E-mail: pagube@med.unibo.it.

Daniela Cota and Giovanni Marsicano contributed equally to this work.

Conflict of interest: The authors have declared that no conflict of interest exists.

Nonstandard abbreviations used: cannabinoid receptor type 1 (CB1); corticotropin-releasing hormone (CRH); cocaine-amphetamine-regulated transcript (CART); digoxigenin (DIG); melaninconcentrating hormone (MCH); energy expenditure (EE); area under the curve (AUC); respiratory quotient $(\mathrm{RQ})$; lean body mass (LBM); dual-energy x-ray absorptiometry (DEXA); in situ

hybridization (ISH); lipoprotein lipase (LPL); the paraventricular nucleus (PVN); neuropeptide Y (NPY); the ventromedial nucleus (VMN); lateral hypothalamic area (LHA); arcuate nucleus (ARC); dorsomedial nucleus (DMN); Agouti-related protein (AGRP).

\section{Introduction}

A combination of central and peripheral mechanisms modulates food intake and energy consumption to maintain metabolism and body composition in mammals. Diseases characterized by impaired energy balance, such as obesity, rank among the most immediate health threats in industrialized countries, creating an urgent need to generate new pharmacologic treatment options $(1,2)$. The discovery of leptin has triggered intensified research efforts in the field of energy homeostasis, leading to a better understanding of a complex network of central and peripheral factors that influence both appetite and energy expenditure (3).

The discovery of cannabinoid receptor type 1 (CB1) and cannabinoid receptro type 2 (CB2), provided a molecular basis for investigating the effects 
of marijuana (Cannabis sativa) and its constituents. Moreover, the characterization of endogenous ligands for cannabinoid receptors (endocannabinoids) along with their biosynthesis and degradation pathways revealed the existence of the endogenous cannabinoid system, which has recently been shown to modulate several physiologic functions $(4,5)$. The appetite-stimulating effect of marijuana in humans has been well known for centuries (6). Several reports have demonstrated that administration of cannabinoids stimulates food intake in animal models $(7,8)$. Both peripheral and central administration of anandamide, one of the major endocannabinoids, increase food intake in rodents $(9-11)$. On the basis of the observation that CB1 and endocannabinoids are present in the brain regions controlling food intake (4), the endogenous cannabinoid system has been proposed as a putative modulator of feeding behavior $(12,13)$. This concept has been further substantiated by the use of specific CB1 antagonists, which provided evidence for the role of CB1 in mediating the orexigenic effect of exogenous or endogenous cannabinoids (14-16). Importantly, the levels of hypothalamic endocannabinoids were shown to be decreased after leptin administration, and the blockade of CB1 was demonstrated to inhibit starvation-induced hyperphagia in mice (17). However, little is known about the putative cross-talks of endocannabinoids and CB1 with the large number of hypothalamic neuropeptides known to regulate appetite. Very recently, additional peripheral targets of the endogenous cannabinoid system, which are involved in energy homeostasis, have been described (18).

Thus, $C B 1$-deficient $\left(\mathrm{CB1}^{-/-}\right)$mice (19) were used in the current study as a model to determine the role of the endogenous cannabinoid system in the regulation of energy balance. By using this animal model as a tool, we carefully compared body weight, body composition, and feeding behavior in the presence and in the absence of $C B 1$ in vivo. In particular, we focused on a potential role of the endogenous cannabinoid system in centrally modulating energy homeostasis via hypothalamic neuropeptides as well as on putative functions of endocannabinoids in adipose tissue.

\section{Methods}

Animals. Male mice deficient for $\mathrm{CB} 1\left(\mathrm{CB1}^{-/-}\right)$and male WT littermates $\left(\mathrm{CB1}^{+/+}\right)$, originally generated and genotyped as described earlier (19), were used. Mice were in a mixed genetic background, with a predominant C57BL/6N contribution (seven backcrossings). In complementary experiments, no differences in body weight were observed between male $\mathrm{CB} 1^{+--}$and $\mathrm{CB1}^{+/+}$littermates at any age (data not shown). Therefore, in all experiments only homozygous mutant mice were used. Mice were individually housed in the animal facility of the Max-Planck-Institute of Psychiatry, Munich, Germany, under standard conditions with a 12:12-hour light/dark cycle (light on, 0600 hours) at $22^{\circ} \mathrm{C}$. All animal procedures complied with the guidelines for the care and use of laboratory animals of the Governments of the States of Bavaria and Brandenburg, Germany.

Weight curves. Fifteen $\mathrm{CB}^{+/+}$and $15 \mathrm{CB1}^{-/-}$littermates were studied. All mice had ad libitum access to pelleted standard mouse chow (Altromin, Lage, Germany) and tap water. Body weight was measured weekly at 0900 hours in all animals starting at 3 weeks of age until 15 weeks of age.

Glucose and hormones measurements. Blood was drawn at 0800 hours from 15 -week-old animals and centrifuged at $1000 \mathrm{~g}$. Plasma glucose levels were measured with the use of the Beckman Glucose Analyzer 2 (Beckman, Palo Alto, California, USA). Plasma insulin and leptin levels were measured with RIA kits (Linco, St. Charles, Michigan, USA).

Analysis of body composition by quantitative NMR. At the end of the evaluation of the body weight curve, animals were killed and the carcasses were analyzed for body composition. The measurements were performed by using NMR technology (Bruker's Minispec MQ10, Houston, Texas, USA). The software to measure body tissue composition was developed by Echo Systems (Houston, Texas, USA) for Eli Lilly (Indianapolis, Indiana, USA). NMR imaging was performed in mice by 7 Tesla Scanner (Bruker). The imaging protocol consisted of $\mathrm{T} 2$-weighted images in all three orientations.

Indirect calorimetry, locomotor activity, and body temperature measurements. Energy expenditure (EE) and respiratory quotient (RQ) were measured for 24 hours, in a different, additional set of six male $\mathrm{CB1}^{-/-}$and six male $\mathrm{CB1}^{+/+}$mice, 16 -weeks-old, by using an open circuitry calorimetry system. For measurements of oxygen consumption $\mathrm{VO}_{2}$ (MAGNOS 16, Hartmann \& Braun, Frankfurt/Main, Germany) and carbon dioxide production $\mathrm{VCO}_{2}$ (URAS 14, Hartmann \& Braun), mice were placed in air-tight respiratory cages, which were continuously ventilated with a flow rate of about $30 \mathrm{l} / \mathrm{h}$. Total $\mathrm{VO}_{2}$ was recorded in 6 -minute intervals for each animal and calculated as described (20). RQ is the ratio of $\mathrm{VCO}_{2}$ to $\mathrm{VO}_{2}$. Weight-specific EE was calculated by dividing $\mathrm{EE}(\mathrm{kJ} / \mathrm{d})$ by the lean body mass (LBM) of the animal and expressed as ( $\mathrm{kJ} / \mathrm{g} \mathrm{LBM} / \mathrm{d})$. LBM was determined by using a dual-energy $x$-ray absorptiometry (DEXA) method (PIXImus, Lunar, Madison, Wisconsin, USA). In a separate set of experiments, performed on a new batch of age-matched mice, core body temperature and motor activity were monitored with a computer-controlled automatic biotelemetry system (Data Sciences International, St. Paul, Minnesota, USA) as described before (21). Briefly, a battery-powered transmitter (TA-F40) was implanted intraperitoneally under isoflurane anesthesia and sterile conditions. After the surgery, mice were housed individually. The assessment of the circadian rhythms of body temperature and locomotor activity started 1 week after the surgery to guarantee complete recovery of the animals. Every 2 minutes for 
48 hours, body temperature was measured and the cumulative activity score for the respective time interval was recorded continuously.

Pair-feeding experiments. For pair-feeding experiments, new batches of male mice were used. Twelve $\mathrm{CB}^{+/+}$and six $\mathrm{CB} 1^{-/-}$littermates were maintained on standard pelleted mouse chow (Altromin). Food intake and body weight were monitored daily at 0900 hours. To measure food intake, the pelleted food was weighed and then placed into the food container of the cage; the food remaining 24 hours later was weighed again and the difference, corrected for the food spillage, represented the daily food intake. Six $\mathrm{CB}^{+/+}$and six $\mathrm{CB} 1^{-/-}$were fed ad libitum, receiving a preweighed amount of food known to be largely in excess of daily consumption. The remaining six $\mathrm{CB1}^{+/+}$ were the pair-fed group that, on each day, received the same amount of food as consumed by six $\mathrm{CB1} 1^{-/-}$littermates on the previous day. The experiments were performed with two different groups of animals: young ( 3 weeks old) and adult (20 weeks old).

In situ bybridization. A new batch of seven male $\mathrm{CB}^{+/+}$ and seven male $C B 1^{-/-}$mice, 16 weeks old, fed ad libitum, were killed and their brains were removed. Hypothalamic coronal sections $(16 \mu \mathrm{m})$ were cut on a cryostat (Microtome HM560, Walldorf, Germany), mounted onto frozen SuperFrost/Plus slides (Menzer-Glaser, Braunschweig, Germany), dried, and stored at $-20^{\circ} \mathrm{C}$, until used. $C B 1 \mathrm{cDNA}$ was produced from a 1530-bp fragment as described (22). MCH cDNA (513bp fragment, GenBank accession AK020723, nucleotides 64-577, forward primer 5'-GGATGGCAAAGATGACTCTCT and reverse primer $5^{\prime}$-CGGACCAACAGGTATCAAACT) was generated by RT-PCR from total mouse brain RNA and was cloned into pBluescript $\mathrm{KS}^{-}$(Stratagene, La Jolla, California, USA). Mouse neuropeptide $Y(N P Y)$ cDNA was an IMAGE clone (number 482891) purchased from Research Genetics-Invitrogen (Karlsruhe, Germany). Rat cocaine-amphetamine-regulated transcript (CART) cDNA (Genbank accession AI112077) was a clone purchased from Research Genetics-Invitrogen and kindly provided by J. Dreyer, University of Fribourg, Switzerland. $C R H$ cDNA was a 530-bp fragment (nucleotides 61-591) of mouse CRH (23) kindly provided by W. Wurst, Max-Planck-Institute of Psychiatry, Munich, Germany. Prepro-orexin riboprobe was generated from a clone kindly provided by T.E. Scammell (Beth Israel Deaconess Medical Center, Boston, Massachusetts, USA). The identity of all cDNAs was checked by sequencing. Restriction enzymes (New England Biolabs, Beverly, Massachusetts, USA) used for linearization, and RNA polymerases (Roche, Mannheim, Germany) used for the generation of each riboprobe were as follows: $\mathrm{CB} 1$ sense, PstI, T7; CB1 antisense, BamHI, T3; MCH sense, HindIII, T7; MCH antisense, XbaI, T3; NPY sense NotI, T7; NPY antisense, EcoRI, T3; CART sense, NotI, T7; CART antisense, EcoRI, T3; CRH sense, BamHI, T7; CRH anti- sense, XbaI, Sp6; prepro-orexin sense, NotI, T3; prepro-orexin antisense, SpeI, T7. According to protocol design, riboprobes were labeled with ${ }^{35} \mathrm{~S}$ or with digoxigenin (DIG), respectively, as described (24).

Single in situ hybridization (ISH) was carried out as described (22). In brief, after pretreatment, hybridization was carried out overnight at $65^{\circ} \mathrm{C}$ in hybridization buffer containing ${ }^{35} \mathrm{~S}$-labeled riboprobe $(35,000-70,000$ $\mathrm{cpm} / \mu \mathrm{l})$. Slides were then washed and exposed on Biomax MR films (Kodak, Stuttgart, Germany). Quantification of mRNA expression for each neuropeptide was performed on autoradiographic films, by using NIH Image program (http://rsb.info.nih.gov/nih-image/). For each area analyzed, at least 4 sections per animal were quantified after image thresholding, and data were expressed as percentage of mean value of control $\mathrm{CB1}^{+/+}$mice. Double ISH was performed as described (24). In brief, after pretreatment, hybridization was carried out in buffer containing the ${ }^{35} \mathrm{~S}$ - and DIG-labeled riboprobes at $54^{\circ} \mathrm{C}$ overnight. After washing, sections were treated with the TSA Biotin System (NEN, Boston, Massachusetts, USA) and incubated with streptavidin-alkaline phosphatase (Roche, Mannheim, Germany). After developing of the chromogenic reaction with Vector Red kit (Vector Laboratories, Burlingame, California, USA), sections were exposed on Biomax MR Films (Kodak) and dipped in NTB-2 photographic emulsion (Kodak) on the following day. After exposure for 5 to 15 days at $4^{\circ} \mathrm{C}$, depending on the riboprobe used, slides were developed and counterstained in toluidine blue. CB1-specific signal was evaluated as described (24). Coexpressing cells were counted at a single-cell resolution. Values were expressed as percentage of CB1-expressing cells per number of cells positive for a specific neuropeptide.

Adipose tissue cell culture. Ten 16-week-old C57BL/6N mice (Charles River, Sulzfeld, Germany) were killed and the epidydimal fat pads were removed and immediately collected in Krebs buffer ( $\mathrm{NaCl} 123 \mathrm{mM}, \mathrm{KCl} 5 \mathrm{mM}$, $\mathrm{CaCl}_{2} 13 \mathrm{mM}$, glucose $5 \mathrm{mM}$, BSA 1.5\%, and HEPES $100 \mathrm{mM})$. Primary adipose cells were cultured as described (25). Briefly, cells were grown in DMEM containing $10 \%$ calf serum, sodium pyruvate $(1 \mathrm{mM})$, L-glutamine $(4 \mathrm{mM})$, and antibiotics and were maintained in $5 \% \mathrm{CO}_{2}$ at $37^{\circ} \mathrm{C}$. After 3 days, differentiation was induced by adding insulin $(1 \mu \mathrm{M})$ and triiodothyronine $(0.2 \mathrm{nM})$ to the medium. Cells were treated after 3 days with the CB1 agonist WIN-55,212 (Tocris, Bristol, UK) or the CB1 antagonist SR 141716A (NIMH Chemical Synthesis and Drug Supply Program) or a combination of both compounds (addition of SR 141716A was 45 minutes before WIN-55,212 treatment) for 48 hours. Controls were treated with vehicle (according to the dilution of the drugs, $0.0001 \%$ of DMSO was added to the medium). Heparin-releasable lipoprotein-lipase (LPL) activity was measured with a commercial kit (CONFLUOLIP total lipase test, Progen, Heidelberg, Germany) according to manufacturer's instructions. Experiments were performed in quadruplicates. 


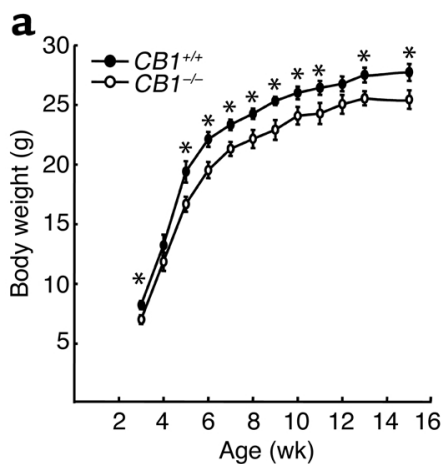

b
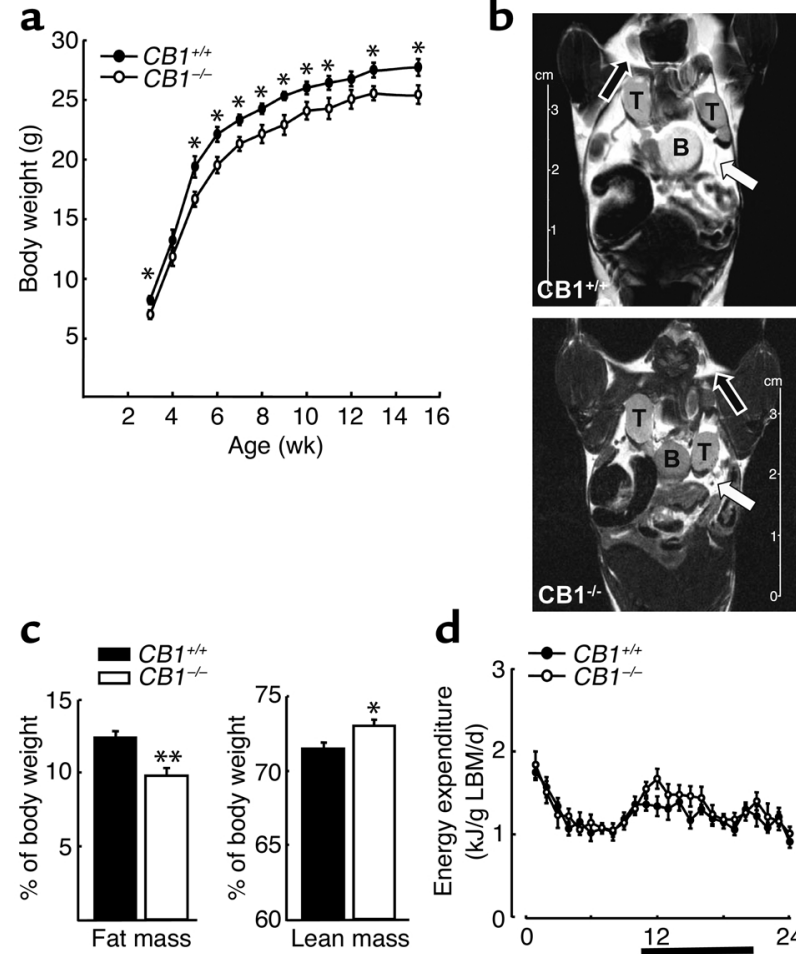

d

cester

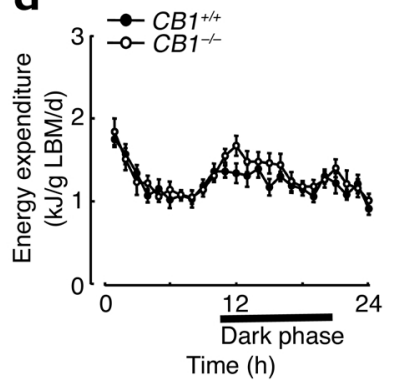

Time (h)

RNA isolation and RT-PCR. Total RNA was extracted from epydidimal fat pads of $\mathrm{CB} 1^{+/+}$and $C B 1^{-/-}$mice and from primary adipocytes cell cultures derived from $\mathrm{C} 57 \mathrm{BL} / 6 \mathrm{~N}$ mice and reverse transcribed as described earlier (26). Primers for CB1 were as follows: CB1 5'-GGTTCTGATCCTGGTGGTGTTGAT and 5'-CCGATGAGACAACAGACTTCT (GenBank accession: MM18374). Primers for $\beta$-actin were as described previously (27). Conditions for CB 1 amplification were 35 cycles, for 1 minute each at $94^{\circ} \mathrm{C}, 55^{\circ} \mathrm{C}$, and $72^{\circ} \mathrm{C}$ and conditions for $\beta$-actin were 35 cycles, for 1 minute each at $94^{\circ} \mathrm{C}, 60^{\circ} \mathrm{C}$, and $72^{\circ} \mathrm{C}$. The PCR products were separated on a $1.5 \%$ agarose gel, and the bands were visualized with ethidium bromide staining. Negative controls for RT-PCR were performed in the absence of reverse transcriptase. Mouse hippocampus RNA was used as a positive control for CB1.

Statistical analysis. All values are reported as means \pm SEM. The data were analyzed partly by one factorial and partly by two factorial univariate or multivariate analyses of variance ([M]ANOVA). In the two factorial ANOVAs, the one factor was a within-subjects factor expressing the repeated measures sequence. In cases of significant factor effects, tests with contrasts or post-hoc Scheffé tests followed to locate pairs of factor levels with significant differences in the examined variables. Unpaired $t$ test was used for the comparison of plasma hormone concentrations between groups of animals and the Mann-Whitney $U$ test was used for the analysis of ISH data. As nominal level of

\section{Figure 1}

Body weight, body composition and $\mathrm{EE}$ of $\mathrm{CB} 1^{-/-}$mice. (a) Body weight curves in male mice starting at 3 weeks of age. Each data point represents mean \pm SEM of 15 mice. ${ }^{*} P<0.05$ vs. $C B 1^{+/+}$littermates. (b) NMR imaging performed in 16-week-old mice. White arrow, visceral fat; black arrow, subcutaneous fat; T, testis; B, bladder. (c) Analysis of body composition by quantitative NMR. Fat mass and lean mass expressed as percentage of the body weight. The columns represent the mean \pm SEM of $15 \mathrm{CB} 1^{+/+}$and $C B 1^{-/-}$ mice, respectively. ${ }^{*} P<0.05$ and ${ }^{*} P<0.005$ vs. $C B 1^{+/+}$controls. (d) $\mathrm{EE}$ in male $\mathrm{CB} 1^{+/+}$and $C B 1^{-/-}$mice. Data are normalized to LBM. Each data point represents mean \pm SEM of six mice.

significance, $\alpha=0.05$ was accepted and corrected accordingly (Bonferroni adjustment) for all posteriori tests (test with contrasts, Scheffé test, etc.). $P$ values less than 0.05 denote statistical significance.

\section{Results}

$\mathrm{CB1}^{-/-}$mice are lighter and leaner than $\mathrm{CB1}^{+/+}$littermates. Male $\mathrm{CB1}^{+/+}$and $\mathrm{CB1}^{-/-}$were fed ad libitum on a standard diet from 3 to 15 weeks of age and body weight was recorded weekly. Starting from week 3, CB1 $11^{-/}$ mice had a lower body weight than $\mathrm{CB}^{+/+}$mice, and $C B 1^{-/-}$mice maintained a significantly reduced body weight as compared to $\mathrm{CB1^{+/+ }}$ throughout the whole period of observation $(P<0.05)$ (Figure 1a). The analysis of body composition of the same animals using quantitative NMR showed a markedly decreased percentage of fat mass and a slightly increased percentage of lean mass in $\mathrm{CB1}^{-/-}$mice compared with $\mathrm{CB1} 1^{+/+}$ $\left(C B 1^{-/-}\right.$fat mass, $9.7 \% \pm 0.55 \%$ vs. $C B 1^{+/+} 12.3 \% \pm 0.51 \%$, $P<0.005)\left(\mathrm{CB1}^{-/-}\right.$lean mass, $73.1 \% \pm 0.43 \%$ vs. $\mathrm{CB}^{+/+}$ $71.6 \% \pm 0.44 \%, P<0.05$ ) (Figure 1, b and c). Plasma leptin levels were significantly lower in $\mathrm{CB1}^{-/-}$mice $\left(\mathrm{CB1}^{-/-}\right.$ leptin, $1.1 \pm 0.1 \mathrm{ng} / \mathrm{ml}$ vs. $C B 1^{+/+} 1.8 \pm 0.3 \mathrm{ng} / \mathrm{ml}$, $P<0.05$ ), whereas plasma insulin and glucose levels were not different between $\mathrm{CB1}^{-/-}$and $\mathrm{CB1}^{+/+}$mice (CB1-/- insulin, $0.9 \pm 0.2 \mathrm{ng} / \mathrm{ml}$ vs. $C B 1^{+/+} 1.0 \pm 0.3$ $\mathrm{ng} / \mathrm{ml}, P>0.05 ; C B 1^{-/-}$blood glucose, $169 \pm 11 \mathrm{mg} / \mathrm{dl}$ vs. $C B 1^{+/+} 164 \pm 11 \mathrm{mg} / \mathrm{dl}, P>0.05$ ) (Table 1 ).

To determine whether differences in thermogenesis or spontaneous physical activity were contributing to the lean phenotype of male $\mathrm{CB1}^{-/-}$mice, body temperature and locomotor activity of both genotypes were studied. Both $\mathrm{CB1}^{-/-}$and $\mathrm{CB1}^{+/+}$mice showed circadian variations in body temperature (time: $\mathrm{F}_{23-184}=23.4$, $P<0.001$ ) and locomotor activity (time: $\mathrm{F}_{23-184}=5.4$,

\section{Table 1}

Plasma glucose and hormone levels in $C B 1^{+/+}$and $C B 1^{-/-}$mice

$\begin{array}{lcc} & C B 1^{+/+} & C B 1^{-/-} \\ \text {Glucose }(\mathrm{mg} / \mathrm{dl}) & 164 \pm 11 & 169 \pm 11 \\ \text { Insulin }(\mathrm{ng} / \mathrm{ml}) & 1.0 \pm 0.3 & 0.9 \pm 0.2 \\ \text { Leptin }(\mathrm{ng} / \mathrm{ml}) & 1.8 \pm 0.3 & 1.1 \pm 0.1^{\mathrm{A}}\end{array}$

Plasma glucose and hormone levels were measured in 15-week-old mice $\left(n=15\right.$ per genotype). ${ }^{A} P<0.05$. 

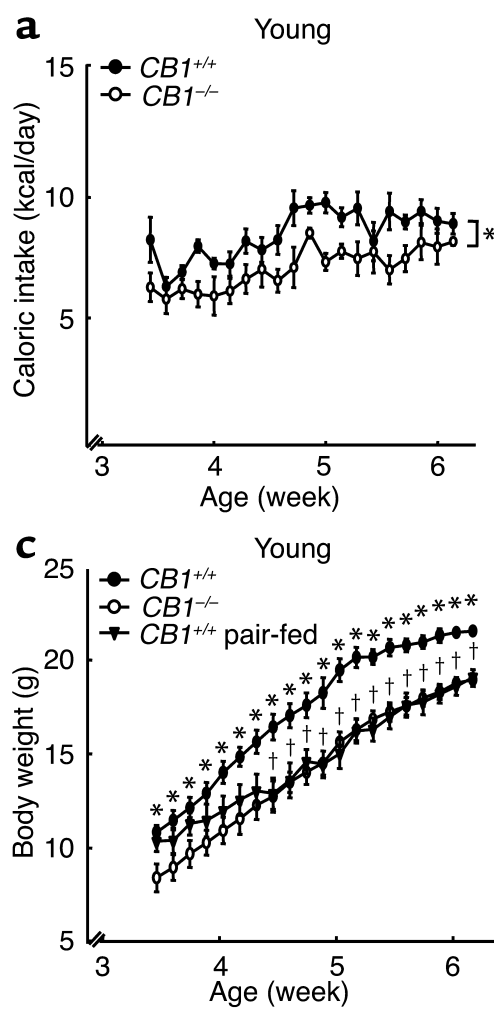

b

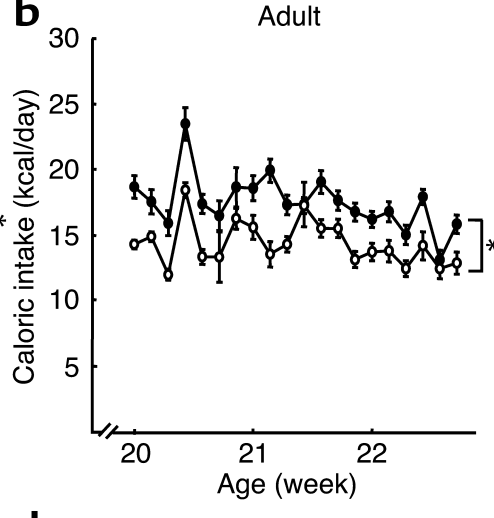

d

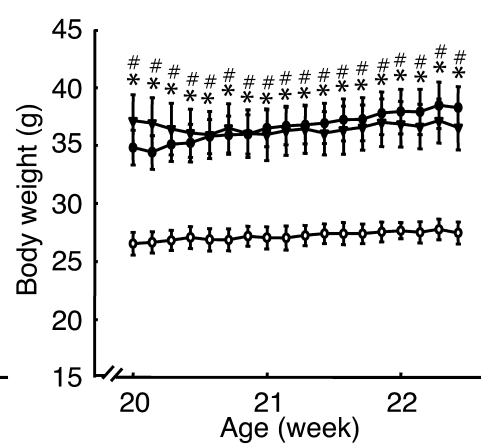

\section{Figure 2}

Food intake and pair-feeding studies in $\mathrm{CB} 1^{-1-}$ mice. (a) Daily energy intake of young $C B 1^{+/+}$and $C B 1^{-/-}$mice. Each data point represents mean \pm SEM of six mice for each group. ${ }^{*} P<0.05$, AUC of caloric intake of $\mathrm{CB} 1^{-/-}$mice vs. $\mathrm{CB} 1^{+/+}$littermates. (b) Daily energy intake of adult $\mathrm{CB}^{-/-}$and $\mathrm{CB} 1^{+/+}$ mice. Each data point represents mean \pm SEM of six mice for each group. ${ }^{*} P<0.05, \mathrm{AUC}$ of caloric intake of $\mathrm{CB}^{-1-}$ mice vs. $\mathrm{CB} 1^{+/+}$littermates. (c) Body weight curves during pair-feeding in young mice. Each data point represents mean \pm SEM of six mice for each group. ${ }^{*} P<0.05 \mathrm{CB} 1^{-1-}$ mice vs. $C B 1^{+/+}$controls; ${ }^{\dagger} P<0.05$ pair-fed $C B 1^{+/+}$mice vs. $\mathrm{CB} 1^{+/+}$controls. (d) Body weight curves during pairfeeding in adult mice. Each data point represents mean \pm SEM of six mice for each group. ${ }^{*} P<0.005$ $C B 1^{-/-}$mice vs. $C B 1^{+/+}$controls; ${ }^{\#} P<0.005 C B 1^{-/-}$ mice vs. pair-fed $C B 1^{+/+}$mice. Body weight did not significantly differ between pair-fed $C B 1^{+/+}$mice and CB $1^{+/+}$controls.
$P<0.001)$, as both parameters increased during the dark period. However, no significant differences were observed between genotypes or in the interaction between time and genotype $(P>0.05)$.

Energy expenditure (EE) was evaluated by performing indirect calorimetry (simultaneous analysis of $\mathrm{O}_{2}$ consumption and $\mathrm{CO}_{2}$ production), reflecting energy combustion and the proportion of fat and carbohydrate oxidation. Both genotypes showed circadian variations in $\mathrm{EE}$ (time: $\mathrm{F}_{23-227}=15.8, P<0.001$ ). However, no significant differences were observed between genotypes either during the light period (genotype: $\mathrm{F}_{1-10}=0.1, P>0.05$; genotype $\times$ time: $\mathrm{F}_{11-107}=0.7$, $P>0.05$ ) (Figure 1d) or during the dark period (genotype: $\mathrm{F}_{1-10}=1.3, P>0.05$; genotype $\times$ time: $\mathrm{F}_{11-110}=1.7$, $P>0.05)$ (Figure 1d).

To further elucidate the mechanisms underlying the body fat deficiency observed in $\mathrm{CB1}^{-/-}$mice, we determined the caloric intake of young ( 3 weeks of age) and adult (20 weeks of age) male $C B 1^{-/-}$vs. $C B 1^{+/+}$

\section{Figure 3}

CB1 transcripts are co-localized with mRNAs of hypothalamic neuropeptides. Bright field micrographs. Vector Red staining, CB1; silver grains, neuropeptides. (a) Co-localization of CB1 and $C R H$ mRNA in PVN. (b) Co-localization of CB1 and CART mRNA in PVN. (c) Co-localization of CB1 and prepro-orexin mRNA in LHA. (d) Co-localization of CB1 and MCH mRNA in LHA. Filled arrow, cell coexpressing CB1 and the respective neuropeptide; open arrow, cell expressing only the respective neuropeptide; asterisk, cell expressing only CB1 mRNA. Scale bars, $10 \mu \mathrm{m}$. mice. A significant reduction in food intake was observed in both young and adult $\mathrm{CB1}^{-/-}$mice compared with $\mathrm{CB}^{+/+}$littermates (caloric intake measured as area under the curve [AUC]; young mice: $\mathrm{CB1}^{-/-}$AUC $65.6 \pm 1.71$ vs. $\mathrm{CB} 1^{+++} 77.6 \pm 1.1, P<0.05$; adult mice: $C B 1^{-/-}$AUC $214.53 \pm 5.85$ vs. $C B 1^{+/+}$ $260.84 \pm 9.12, P<0.05$ ) (Figure 2, a and b). Pair-feeding experiments were performed to unmask the putative contribution of impaired metabolic processes to the lean phenotype of $\mathrm{CB1} 1^{-/-}$mice, in addition to their decreased caloric intake described above.

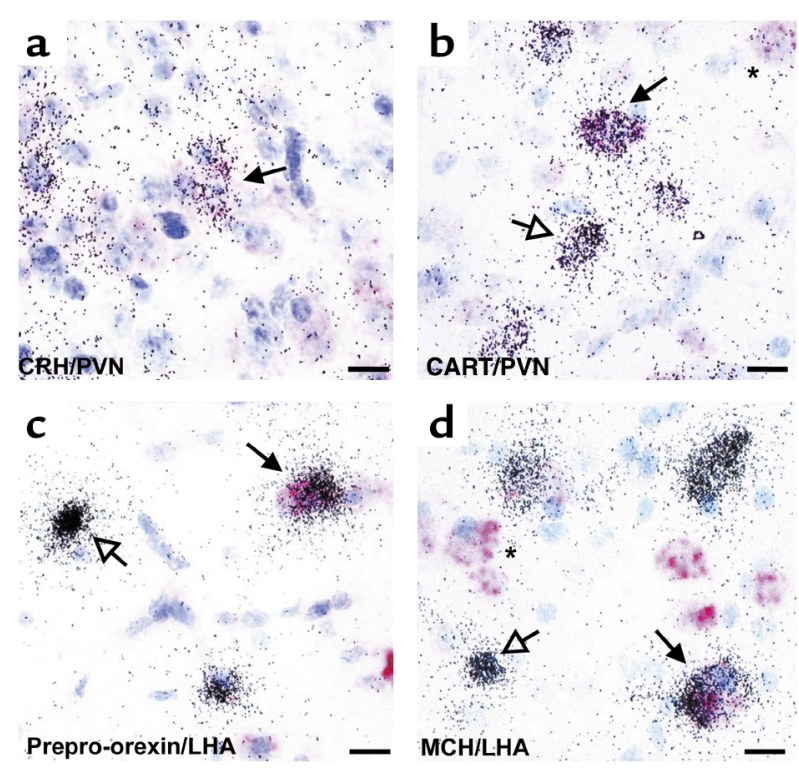


Table 2

Coexpression of CB1 and feeding controlling neuropeptides in hypothalamus

\begin{tabular}{lccc}
\hline & $\begin{array}{c}\text { Area of } \\
\text { hypothalamus }\end{array}$ & $\begin{array}{c}\text { Cells coexpressing } \\
\text { neuropeptide } \\
\text { and CB1 (\%) }\end{array}$ & NC \\
CRH & PVN & 51.4 & 418 \\
CART & PVN & 52.4 & 212 \\
CART & DMN/LHA & 24.6 & 138 \\
Prepro-orexin & LHA & 7.5 & 241 \\
MCH & LHA & 4.2 & 1033
\end{tabular}

CB1, cannabinoid receptor type 1 ; NC, number of cells counted; $\mathrm{CRH}$, corticotropin-releasing hormone; PVN, paraventricular nucleus; CART, cocaineamphetamine-regulated transcript; DMN, dorsomedial nucleus; LHA, lateral hypothalamic area; $\mathrm{MCH}$, melanin-concentrating hormone.

Under caloric restriction based on pair-feeding conditions, 3-week-old $\mathrm{CB1}^{+/+}$mice showed a significant decrease in body weight $(P<0.05)$. After 1 week of pair feeding, differences in body weight between pairfed $\mathrm{CB1}^{+/+}$and $\mathrm{CB1}^{-/-}$mice were abolished, whereas $C B 1^{+/+}$mice with ad libitum access to food maintained their higher body weight $(P<0.05)$ (Figure $2 c)$. Notably, pair-feeding experiments of 20-week-old $\mathrm{CB} 1^{+/+}$mice did not cause a significant decrease of body weight compared with $\mathrm{CB1}^{-/-}$littermates. Body weight of adult $\mathrm{CB1}^{-/-}$mice after this pair-feeding experiment was still lower compared with their $\mathrm{CB1}^{+++}$ littermates $(P<0.005)$ (Figure $2 \mathrm{~d})$.
Characterization of hypothalamic neuropeptide expression patterns in $\mathrm{CB}^{-/-}$mice. To investigate possible hypothalamic pathways responsible for the decreased food intake in $\mathrm{CB}^{-/}$mice, ISH experiments were performed on hypothalamic tissue samples derived from male $\mathrm{CB1}^{+/+}$mice to co-localize hypothalamic $\mathrm{CB} 1$ mRNA with several neuropeptides known to be involved in feeding regulation.

ISH for CB1 confirmed our earlier findings that CB1 hybridization signals were detectable in the medial and lateral preoptic nucleus, the paraventricular nucleus $(\mathrm{PVN})$, the ventromedial nucleus (VMN), and in the lateral hypothalamic area (LHA) (22). As expected, CRHexpressing cells were found in the medial preoptic area and PVN (28) and the expression of NPY mRNA was limited to the arcuate nucleus (ARC) (29). CART mRNA was abundantly expressed in the hypothalamus, especially in the supraoptic nucleus, PVN, VMN, dorsomedial nucleus (DMN), LHA, and ARC (30), whereas the expression of prepro-orexin and $\mathrm{MCH}$ mRNAs was restricted to the neurons localized in LHA and in the zona incerta $(31,32)$. In ISH experiments, corresponding sense RNA probes did not give any detectable signals (data not shown).

CB1 was found to be co-localized with CRH, CART, prepro-orexin, and $\mathrm{MCH}$ (Figure 3), whereas no coexpression was found with NPY-positive neurons in ARC (data not shown). In PVN, 51.4\% of CRH-positive and $52.4 \%$ of CART-positive neurons expressed CB1 mRNA. In DMN and LHA, 24.6\% of CART-posi-

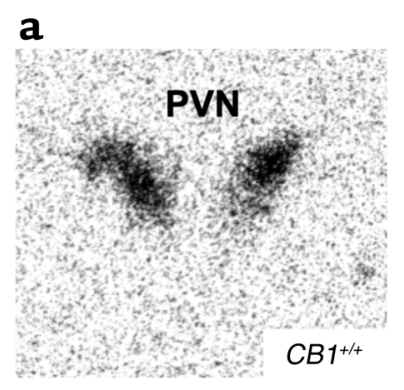

C

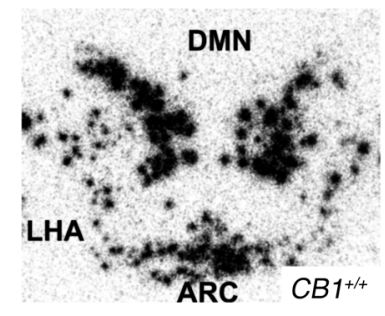

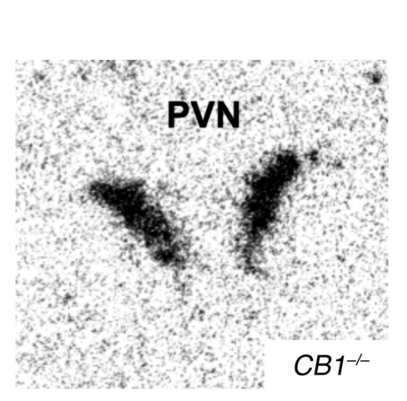

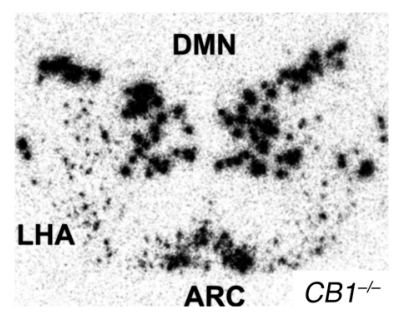

b

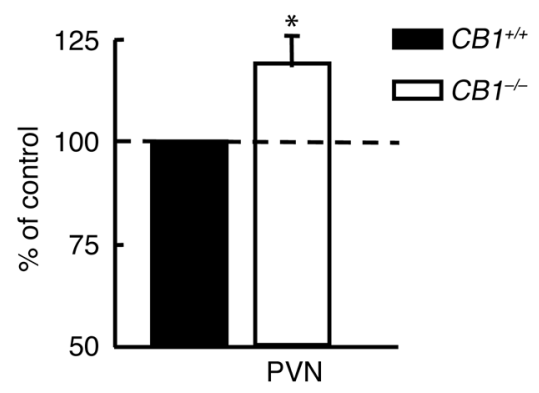

d

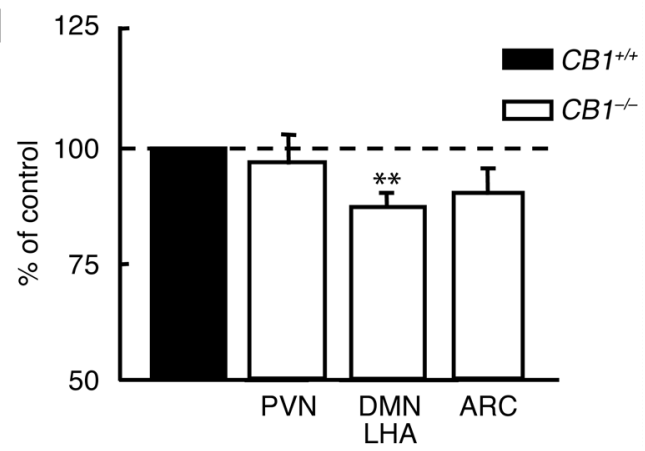

Figure 4

Altered expression of hypothalamic neuropeptides transcripts in $C B 1^{-/-}$mice. (a) Representative autoradiographic images showing upregulation of CRH mRNA in the PVN of $C B 1^{-/-}$hypothalamus. (b) Densitometric quantification by image analysis of areas of CRH mRNA expression as percentage of control by using four sections from seven animals in each group. ${ }^{*} P<0.05$ vs. $C B 1^{+/+}$control. (c) Representative autoradiographic images showing downregulation of CART mRNA in the DMN, LHA, and ARC of CB1 ${ }^{-/-}$hypothalamus. (d) Densitometric quantification by image analysis of areas of CART mRNA expression as percentage of control by using four sections from seven animals in each group. ${ }^{*} P<0.005 \mathrm{vs.} C B 1^{+/+}$control. 

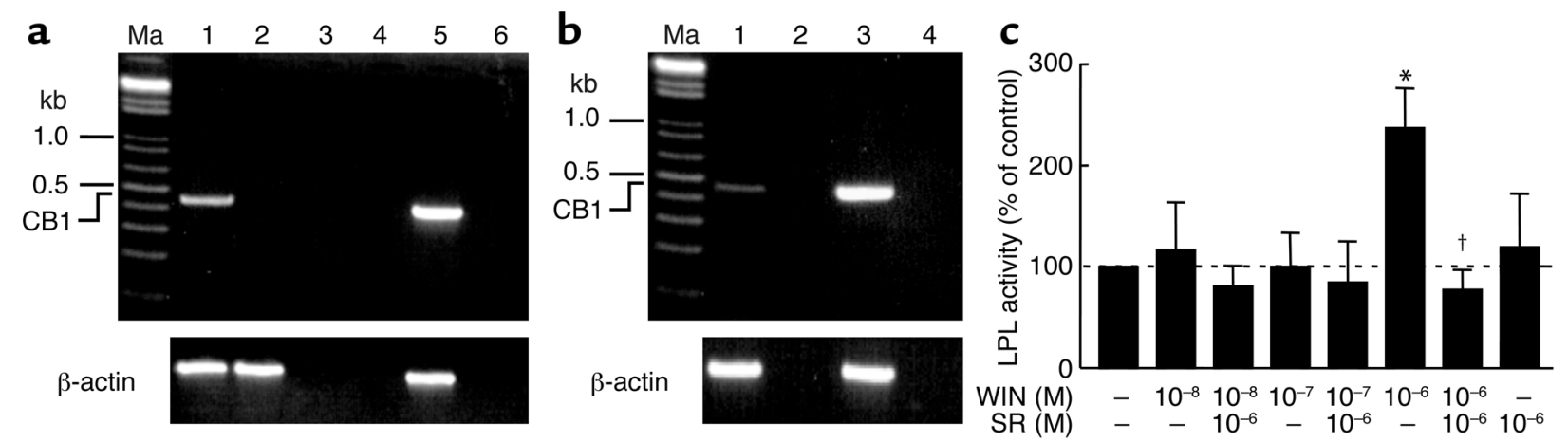

Figure 5

Functional $C B 1$ is expressed in adipocytes. (a) RT-PCR for CB1 performed on $C B 1^{+/+}$and $C B 1^{-/-}$epididymal fat pads. Ma, marker; lane 1 , $C B 1^{+/+}$; lane 2, $C B 1^{-{ }^{-}}$; lane 3, negative control for $C B 1^{+/+}$; lane 4, negative control for $C B 1^{-l^{-}}$; lane 5, hippocampus; lane 6, water. (b) RT-PCR for CB1 performed on primary adipocyte cell cultures from C57BL/6N mice. Ma, marker; lane 1, C57BL/6N adipocytes; lane 2, negative control; lane 3, hippocampus; lane 4, water. (c) Effects of different doses of the CB1 agonist WIN-55,212 (WIN) and CB1 antagonist SR 141716A (SR) on heparin-releasable LPL activity (expressed as percentage of vehicle control) in primary adipocyte cells from C57BL/ $6 \mathrm{~N}$ mice. ${ }^{*} P<0.05$ compared with vehicle control. ${ }^{\dagger} P<0.05$ compared with $10^{-6} \mathrm{M} \mathrm{WIN}$.

tive cells expressed CB1 mRNA, in LHA 7.5\% of prepro-orexin-positive neurons and $4.2 \%$ of $\mathrm{MCH}$-positive cells coexpressed CB1 mRNA (Table 2).

CRH mRNA in the PVN of male $C B 1^{-/-}$mice was $19.5 \% \pm 7.5 \%$ higher compared with $C B 1^{+/+}$littermates $(P<0.05)$ (Figure 4, a and b). A $14.2 \% \pm 3.3 \%$ lower expression of CART mRNA was observed in DMN and LHA of $\mathrm{CB}^{-/-}$mice compared with $\mathrm{CB1}^{+/+}$littermates $(P<0.005)$ (Figure $4, \mathrm{c}$ and $\mathrm{d})$. No differences were observed between the two genotypes regarding the levels of expression of prepro-orexin, $\mathrm{MCH}$, or NPY (data not shown).

CB1 is expressed in fat tissue and CB1 agonists stimulate lipogenesis in vitro. CB1 mRNA was found in ex vivo epidydimal fat pads from male $\mathrm{CB1}^{+/+}$, but not from $C B 1^{-/}$mice (Figure $5 \mathrm{a}$ ) and its expression was maintained in in vitro primary adipocyte cell cultures derived from C57BL/6N mice (Figure $5 \mathrm{~b}$ ). Stimulation of primary adipocyte cells (derived from C57BL/6N epidydimal fat) with the CB1 agonist WIN-55,212 dose-dependently increased lipoprotein lipase activity, and this effect was blocked by the preincubation with the CB1 selective antagonist SR 141716A, demonstrating a CB1-mediated effect (Figure 5c).

\section{Discussion}

The obesity epidemic is currently developing into a major health problem of industrialized countries. Effective pharmacologic treatment options are needed to limit its harmful consequences. Despite the dramatic progress in obesity research, a safe and potent weight-reducing drug is still not available. The optimism triggered by the discovery of leptin in 1994 was soon overshadowed by clinical studies showing that the fat-reducing effects of leptin were limited to a handful of patients with congenital leptin deficiency (33). Currently, other clinical candidates targeting neuroendocrine energy balance mechanisms are under investigation (34). In this context, the endoge- nous cannabinoid system represents a new and promising drug target $(13,35)$.

Our current study substantiates this concept by demonstrating that the germline deletion of CB1 in mice results in a phenotype characterized by decreased body weight, reduced fat mass, and hypophagia. The fact that the simultaneous deletion of the two most potent orexigenic neuropeptides known to date, NPY and Agouti-related protein (AGRP), failed to produce a lean phenotype, demonstrates the redundancy of neuroendocrine factors driving energy intake (36). Our study, however, indicates that even the high number of endogenous orexigenic factors is unable to compensate for the lack of endogenous cannabinoid action, reflecting its crucial role in balancing energy homeostasis.

The lean phenotype of $\mathrm{CB1}^{-/-}$mice is likely to be predominantly caused by reduced orexigenic drive throughout their lifetime, which would be in agreement with the reported role of the endogenous cannabinoid system for hyperphagic response to starvation (17).

Reduced body weight in young and adult $\mathrm{CB1}^{-/-}$ mice might be a direct result of the decreased caloric intake, which, in turn, might be due to the alterations in the central orexigenic drive as a consequence of the lack of $C B 1$ in hypothalamic circuits. However, the differing pair-feeding results in young and mature animals (Figure 2) point to an essential role of orexigenic drive during early ages and suggest that additional, food intake-independent mechanisms also contribute to the lean phenotype of adult $\mathrm{CB1}^{-/-}$mice. Although these observations might be merely due to adaptation efforts of the body weight control system, they may point to a previously unknown function of the endogenous cannabinoid system within peripheral mechanisms regulating energy balance. Besides the obvious fact that adipose tissue represents a major determinant of numerous metabolic processes, adipocytes caught our attention 
for their ability to store exogenous cannabinoids, which are lipophylic substances, for up to 2 weeks (37). Our data indicate that mRNA coding for CB1 is expressed in epidydimal fat pads. Moreover, CB1 expressed by primary adipocytes cultured from C57BL/6N mice appears to be functional because lipogenesis can be induced by specific stimulation of the receptor. These observations, together with the presence of monoacylglycerol lipase in fat tissue, one of the main endocannabinoid-degrading enzymes $(38,39)$, strongly support adipose tissue as a novel physiologic and pharmacologic target for cannabinoid action. Therefore, our results suggest that the reduced body fat in $\mathrm{CB1}^{-/-}$mice might be determined by both hypothalamic alterations and impaired adipocyte function. Notably, a recent study showed that administration of the CB1 antagonist SR $141716 \mathrm{~A}$ leads to a marked and sustained reduction of adiposity in diet-induced obese mice, which could not be explained by the transient reduction in food intake caused by this drug (40). It is also intriguing that endocannabinoids derived from the gastrointestinal tract appear to be able to modulate feeding behavior (18) and it seems likely that CB1 expressed on adipocytes might be one of the effectors of these and other sources of endocannabinoids.

On the other hand, the altered expression of hypothalamic neuropeptides in $\mathrm{CB1}^{-/-}$mice supports a role of the endogenous cannabinoid system in the central regulation of food intake. $\mathrm{CB1}^{-/-}$mice show higher levels of CRH mRNA, a neuropeptide known to inhibit food intake as well as to influence energy balance via the sympathetic nervous system and the hypothalamopituitary-adrenal axis (41). Albeit, NPY fibers project from the ARC to CRH neurons in PVN (42), it is not yet clear whether the anorectic effect of $\mathrm{CRH}$ might be inhibited by NPY signaling. Neither is CB1 expressed in NPY neurons, nor did $\mathrm{CB1}^{-/-}$mice show altered basal levels of NPY mRNA expression. In addition, the CB1 antagonist SR 141716A still inhibits starvationinduced hyperphagia in $\mathrm{NPY}^{-/-}$mice (17). Altogether, these data indicate that the effects of hypothalamic endocannabinoids on energy balance might partially be mediated by $\mathrm{CRH}$, but those effects are likely to be independent from NPY.

An unexpected result of our ISH analysis was the reduced CART expression in $\mathrm{CB1}^{-/-}$mice. Initial evidence suggested an anorexigenic role for this peptide and decreased hypothalamic CART expression was found in animal models with an obese phenotype (43). As leptin is a positive regulator of hypothalamic CART mRNA expression (43), $\mathrm{CB1}^{-/-}$mice might show reduced CART expression because of the decreased circulating levels of the hormone, overall reflecting a physiologic compensation effort in reaction to decreased body fat stores. However, recent data challenged previous observations on the appetite-inhibiting effect of CART, showing that intrahypothalamic injection of the peptide might even increase food intake (44). Moreover, the administration of the CB1 antagonist SR 141716A did not affect feeding behavior in $C A R T^{-/-}$mice (45). Therefore, our results seem to confirm that CART might play a crucial role in the hypothalamic mediation of orexigenic endocannabinoid action. The coexpression of CB1 with CRH and CART suggests a direct influence of the endocannabinoids on the expression or function of these neuropeptides.

The exact mechanisms underlying the effects of the endogenous cannabinoid system on food intake and fat storage remain to be elucidated and further experiments are needed to clarify these mechanisms both at central and peripheral levels. The generation of tissue-specific mutant mice for CB1 will help to dissect the relative influence of the endogenous cannabinoid system on different central neuronal circuits and on different peripheral tissues in regulating energy homeostasis. Another interesting aspect, which is still to be fully explained, is the origin of a mild gender specificity of the lean phenotype, which is less pronounced in female $\mathrm{CB} 1^{-/-}$mice (unpublished data). In contrast to our results, previous investigations on $\mathrm{CB}^{-/-}$mice reported no changes in body weight between genotypes, probably because of differences in the inbred strains used and/or the lack of the analysis of homogenous subcohorts (e.g., males vs. females) $(17,46,47)$. However, sexual differences are rather common features observed in other genetically engineered animal models of body weight regulation, such as $M C 3-R^{-/-}$ and $\mathrm{CART}^{-/-}$mice $(48,49)$.

Currently, clinical phase III trials (http://www. clinicaltrials.gov) are ongoing to assess the effects of the CB1 selective antagonist SR141716A on body weight in obese patients with and without dislipidemia or type 2 diabetes mellitus. Our findings, showing that the endogenous cannabinoid system modulates energy homeostasis via a dual mechanism, intriguingly suggests that CB1 antagonists will be able to centrally target food intake regulation as well as peripherally block lipogenetic processes, paving the way for one of the most promising clinical candidates to fight obesity.

\section{Acknowledgments}

This work was supported by a grant Giovani Ricercatori, University of Bologna, and in part by Fondazione Cassa di Risparmio, Bologna, Italy. Additional support was given by a grant from the German Research Council (to B. Lutz). We thank M.L. Heiman (Endocrine Research, Eli Lilly and Co., Indianapolis, Indiana, USA) for the body composition analysis; C. Pagano (University of Padova, Padova, Italy) for the glucose levels measurements; H. Hermann, B. Wölfel, A. Daschner, and C. Plaue for technical help; J. Dreyer and A. Copper for the gift of CART; and T.E. Scammell and W. Wurst for the gifts of prepro-orexin and CRH clones, respectively. 
1. Flegal, K.M., Carroll, M.D., Ogden, C.L., and Johnson, C.L. 2002. Prevalence and trends in obesity among US adults, 1999-2000. JAMA 288:1723-1727.

2. Yanovski, S.Z., and Yanovski, J.A. 2002. Obesity. N. Engl. J. Med. 346:591-602.

3. Zhang, Y., et al. 1994. Positional cloning of the mouse obese gene and its human homologue. Nature. 372:425-432.

4. Howlett, A.C., et al. 2002. International Union of Pharmacology. XXVII. Classification of cannabinoid receptors. Pharmacol. Rev. 54:161-202.

5. Lutz, B. 2002. Molecular biology of cannabinoid receptors. Prostaglandins Leukot. Essent. Fatty Acids. 66:123-142.

6. Abel, E.L. 1975. Cannabis: effects on hunger and thirst. Behav. Biol. 15:255-281.

7. Williams, C.M., Rogers, P.J., and Kirkham, T.C. 1998. Hyperphagia in pre-fed rats following oral delta9-THC. Physiol Behav. 65:343-346.

8. Koch, J.E. 2001. Delta(9)-THC stimulates food intake in Lewis rats effects on chow, high-fat and sweet high-fat diets. Pharmacol. Biochem. Behav. 68:539-543.

9. Williams, C.M., and Kirkham, T.C. 1999. Anandamide induces overeating: mediation by central cannabinoid (CB1) receptors. Psychopharmacology (Berl). 143:315-317.

10. Jamshidi, N., and Taylor, D.A. 2001. Anandamide administration into the ventromedial hypothalamus stimulates appetite in rats. Br.J. Pharmacol. 134:1151-1154.

11. Hao, S., Avraham, Y., Mechoulam, R., and Berry, E.M. 2000. Low dose anandamide affects food intake, cognitive function, neurotransmitter and corticosterone levels in diet-restricted mice. Eur. J. Pharmacol. 392:147-156.

12. Mechoulam, R., and Fride, E. 2001. A hunger for cannabinoids. Nature. 410:763-765.

13. Cota, D., et al. 2003. The endogenous cannabinoid system as a modulator of food intake. Int. J. Obes. Relat. Metab. Disord. 27:289-301.

14. Simiand, J., Keane, M., Keane, P.E., and Soubrie, P. 1998. SR 141716, a CB1 cannabinoid receptor antagonist, selectively reduces sweet food intake in marmoset. Behav. Pharmacol. 9:179-181.

15. Colombo, G., et al. 1998. Appetite suppression and weight loss after the cannabinoid antagonist SR 141716. Life Sci. 63:L113-L117.

16. Freedland, C.S., Poston, J.S., and Porrino, L.J. 2000. Effects of SR141716A, a central cannabinoid receptor antagonist, on food-maintained responding. Pharmacol. Biochem. Behav. 67:265-270.

17. Di Marzo, V., et al. 2001. Leptin-regulated endocannabinoids are involved in maintaining food intake. Nature. 410:822-825.

18. Gomez, R., et al. 2002. A peripheral mechanism for CB1 cannabinoid receptor-dependent modulation of feeding. J. Neurosci. 22:9612-9617.

19. Marsicano, G., et al. 2002. The endogenous cannabinoid system controls extinction of aversive memories. Nature. 418:530-534.

20. Klaus, S., Munzberg, H., Truloff, C., and Heldmaier, G. 1998. Physiology of transgenic mice with brown fat ablation: obesity is due to lowered body temperature. Am. J. Physiol. 274:R287-R293.

21. Linthorst, A.C.E., Karanth, S., Barden, N., Holsboer, F., and Reul, J.M.H.M. 1999. Impaired glucocorticoid receptor function evolves in aberrant physiological responses to bacterial endotoxin. Eur. J. Neurosci. 66:143-151.

22. Marsicano, G., and Lutz, B. 1999. Expression of the cannabinoid receptor $\mathrm{CB} 1$ in distinct neuronal subpopulations in the adult mouse forebrain. Eur. J. Neurosci. 11:4213-4225.

23. Seasholtz, A., Bourbonais, F.J., Harnden, C.E., and Camper, S.A. 1991. Nucleotide sequence and expression of the mouse corticotropin-releasing hormone gene. Mol. Cell. Neurosci. 2:266-273.

24. Hermann, H., Marsicano, G., and Lutz, B. 2002. Coexpression of the cannabinoid receptor type 1 with dopamine and serotonin receptors in distinct neuronal subpopulations of the adult mouse forebrain. New roscience. 109:451-460.

25. Ailhaud, G. 2001. Adipose tissue protocols. Humana Press. Totowa, New Jersey, USA. 334 pp.

26. Pagotto, U., et al. 1995. Expression and localization of endothelin-1 and endothelin receptors in human meningiomas. Evidence for a role in tumoral growth. J. Clin. Invest. 96:2017-2025.
27. Matsumoto, F., et al. 2002. Effects of nutrition on the cell survival and gene expression of transplanted fat tissues in mice. Biochem. Biophys. Res. Commun. 295:630-635.

28. Olschowka, J.A., O’Donohue, T.L., Mueller, G.P., and Jacobowitz, D.M. 1982. The distribution of corticotropin releasing factor-like immunoreactive neurons in rat brain. Peptides. 3:995-1015.

29. Allen, Y.S., et al. 1983. Neuropeptide Y distribution in the rat brain. Science. 221:877-879.

30. Couceyro, P.R., Koylu, E.O., and Kuhar, M.J. 1997. Further studies on the anatomical distribution of CART by in situ hybridization. J. Chem. Neuroanat. 12:229-241.

31. de Lecea, L., et al. 1998. The hypocretins: hypothalamus-specific peptides with neuroexcitatory activity. Proc. Natl. Acad. Sci. U. S. A. 95:322-327.

32. Bittencourt, J.C., et al. 1992. The melanin-concentrating hormone system of the rat brain: an immuno- and hybridization histochemical characterization. J. Comp. Neurol. 319:218-245.

33. Farooqi, I.S., et al. 1999. Effects of recombinant leptin therapy in a child with congenital leptin deficiency. N. Engl. J. Med. 341:879-884.

34. Dhillo, W.S., and Bloom, S.R. 2001. Hypothalamic peptides as drug targets for obesity. Curr. Opin. Pharmacol. 1:651-655.

35. Berry, E.M., and Mechoulam, R. 2002. Tetrahydrocannabinol and endocannabinoids in feeding and appetite. Pharmacol. Ther. 95:185-190.

36. Qian, S., et al. 2002. Neither agouti-related protein nor neuropeptide $\mathrm{Y}$ is critically required for the regulation of energy homeostasis in mice. Mol. Cell Biol. 22:5027-5035.

37. Kreuz, D.S., and Axelrod, J. 1973. Delta-9-tetrahydrocannabinol: localization in body fat. Science. 179:391-393.

38. Karlsson, M., Contreras, J.A., Hellman, U., Tornqvist, H., and Holm, C. 1997. cDNA cloning, tissue distribution, and identification of the catalytic triad of monoglyceride lipase. Evolutionary relationship to esterases, lysophospholipases, and haloperoxidases. J. Biol. Chem. 272:27218-27223.

39. Dinh, T.P., et al. 2002. Brain monoglyceride lipase participating in endocannabinoid inactivation. Proc. Natl. Acad. Sci. U. S. A. 99:10819-10824.

40. Ravinet, T.C., et al. 2003. Anti-obesity effect of SR141716, a CB1 receptor antagonist, in diet-induced obese mice. Am. J. Physiol. Regul. Integr. Comp. Physiol. 284:R345-R353.

41. Inui, A. 1999. Feeding and body-weight regulation by hypothalamic neuropeptides-mediation of the actions of leptin. Trends Neurosci. 22:62-67.

42. Li, C., Chen, P., and Smith, M.S. 2000. Corticotropin releasing hormone neurons in the paraventricular nucleus are direct targets for neuropeptide $Y$ neurons in the arcuate nucleus: an anterograde tracing study. Brain Res. 854:122-129.

43. Kristensen, P., et al. 1998. Hypothalamic CART is a new anorectic peptide regulated by leptin. Nature. 393:72-76.

44. Abbott, C.R., et al. 2001. Evidence of an orexigenic role for cocaine- and amphetamine-regulated transcript after administration into discrete hypothalamic nuclei. Endocrinology. 142:3457-3463

45. Kunos, G., et al. 2002. Endocannabinoids and appetite: possible interactions with other neurotransmitter systems. Symposium on the Cannabinoids. Burlington, Vermont, USA, International Cannabinoid Research Society. (Abstr.)

46. Zimmer, A., Zimmer, A.M., Hohmann, A.G., Herkenham, M., and Bonner, T.I. 1999. Increased mortality, hypoactivity, and hypoalgesia in cannabinoid CB1 receptor knockout mice. Proc. Natl. Acad. Sci. U. S. A. 96:5780-5785

47. Ledent, C., et al. 1999. Unresponsiveness to cannabinoids and reduced addictive effects of opiates in CB1 receptor knockout mice. Science. 283:401-404

48. Chen, A.S., et al. 2000. Inactivation of the mouse melanocortin-3 receptor results in increased fat mass and reduced lean body mass. Nat. Genet. 26:97-102

49. Asnicar, M.A., et al. 2001. Absence of cocaine- and amphetamine-regulated transcript results in obesity in mice fed a high caloric diet. Endocrinology. 142:4394-4400. 